\title{
Communication
}

\section{Citrate-Coated Platinum Nanoparticles Exhibit a Primary Particle-Size Dependent Effect on Stimulating Melanogenesis in Human Melanocytes}

\author{
Shilpi Goenka ${ }^{1, *(1)}$ and Jimmy Toussaint ${ }^{2}$ \\ 1 Department of Biomedical Engineering, Stony Brook University, Stony Brook, NY 11794-5281, USA \\ 2 Department of Emergency Medicine, Stony Brook University, Stony Brook, NY 11794-8434, USA; \\ jimmytoussaint@gmail.com \\ * Correspondence: shilpi.goenka@stonybrook.edu
}

Received: 7 October 2020; Accepted: 5 November 2020; Published: 9 November 2020

\begin{abstract}
Hypopigmentation disorders due to an underproduction of the pigment melanin by melanocytes cause uneven skin coloration, while in hair follicles they cause grey hair. There is a need for novel materials which can stimulate melanogenesis in the skin and hair for personal care use. While titanium dioxide, gold and silver nanoparticles have been extensively used for applications in cosmetic and personal-care products (PCP), the use of relatively inert platinum nanoparticles (PtNPs) has remained underappreciated. PtNPs have been reported to be a mimetic of the enzyme catechol oxidase with small size PtNPs reported to exhibit a higher catechol oxidase activity in a cell-free system, but no testing has been conducted in melanocytes to date. Herein, we have investigated if PtNPs of two sizes (SPtNP: $5 \mathrm{~nm}$; LPtNP: $50 \mathrm{~nm}$ ) might have an effect on melanogenesis. To this end, we have used MNT-1 human melanoma cells and primary human melanocytes from moderately-pigmented skin (HEMn-MP). Both SPtNP and LPtNP were nontoxic over a concentration range $6.25-25 \mu \mathrm{g} / \mathrm{mL}$, hence these concentrations were used in further experiments. Both PtNPs stimulated higher extracellular melanin levels than control; SPtNP at concentrations 12.5 and $25 \mu \mathrm{g} / \mathrm{mL}$ significantly stimulated higher levels of extracellular melanin as compared to similar concentrations of LPtNP in MNT-1 cells, in the absence of ROS generation. The effects of PtNPs on melanin secretion were reversible upon removal of PtNPs from the culture medium. The results of primary particle size-specific augmentation of extracellular melanin by SPtNPs were also validated in HEMn-MP cells. Our results thus provide a proof-of-principle that SPtNP might hold potential as a candidate for the treatment of white skin patches, for sunless skin-tanning and for use in anti-greying hair products in cosmetics.
\end{abstract}

Keywords: platinum nanoparticles; particle size; MNT-1 human melanoma cells; primary human melanocytes from moderately-pigmented skin; extracellular melanin; pro-pigmentation

\section{Introduction}

Melanin, a hetero-polymeric pigment responsible for coloration and for UV photo-protection, radical scavenging and other biological benefits, is synthesized within vesicles called melanosomes of specialized cells called melanocytes, and is present in the skin, hair and eyes [1-4]. The enzyme tyrosinase catalyzes the rate-limiting step in the synthesis of melanin pigment within melanosomes by catalyzing the hydroxylation of L-tyrosine to L-DOPA (L-3,4 dihydroxyphenylalanine) and conversion of L-DOPA to Dopaquinone [5]. Upon completion of biosynthesis of melanin within melanosomes, they are exported via cytoskeletal conduits called dendrites, to the surrounding keratinocytes with which they form the epidermal-melanin unit [6]. Similar to the epidermis, the melanocytes in the 
hair matrix also possess dendrites and communicate with cortical keratinocytes, although the hair melanocytes interact with fewer keratinocytes as compared to skin [7]. An underproduction of the pigment causes hypopigmentation disorders such as vitiligo and leukoderma characterized by a decline in melanin production due to loss of melanocytes accompanied by oxidative stress and inflammation. Furthermore, burn injuries also cause skin hypopigmentation which is characterized by a loss of melanocyte dendricity [8]. The white-colored skin patches due to hypopigmentation caused by disease or injuries are associated with the development of psychosocial complications and affect the quality of life. Compounds which target later steps in the melanogenesis pathway to stimulate pigmentation are desirable since the synthesized melanin is transported and eventually phagocytosed by keratinocytes in melanocytes [9]. Current treatments to increase skin pigmentation comprise of indoor tanning involving the use of artificial UV irradiation or chemical method using dihydroxyacetone (DHA), an active ingredient in spray-on tanning lotions and used as a 'browning agent' for topical use [10]. However, indoor tanning has disadvantages as it can increase chances of skin cancer [11]. DHA also exhibits severe side-effects and has been shown to cause DNA damage and apoptosis in keratinocytes [10]. Few other reports have also described the use of synthetic melanin, $\alpha$-MSH analogs [12] or melanotropic peptides [13] for skin-tanning applications.

Nanotechnology-based ingredients have been used extensively in the cosmetic industry ranging from skin-care to oral care products [14-16]. The cosmetic company L'Oréal S.A. ranks sixth in the USA for the number of patents issued on nanotechnology-based products for cosmetic use [17]. Different-sized titanium dioxide nanoparticles have been used in sunscreen products [18]. Gold nanoparticles have been used for antioxidant and antiaging benefits in cosmetic products [19]. Silver nanoparticles have been used extensively in several personal-care products [20]. Despite the widespread popularity of these noble metal nanoparticles, the use of platinum nanoparticles (PtNPs) have received much less attention in terms of biological uses [21]. Bionyx skin care is the only cosmetic company that has an exclusive line of platinum-infused skin care products [22].

PtNPs have emerged as a novel class of metal NPs with unique physicochemical properties [23]; they have demonstrated anti-inflammatory activity [24], radical scavenging and antioxidant activity in several previous studies [25-29]. Colloidal platinum was reported to protect intestinal epithelial cells from oxidative damage in a previous report [30]. The size-effect of PtNPs have been also explored in previous studies; for example, small sized PtNPs showed higher anticancer efficacy when combined with photothermal therapy [31] and higher cytotoxicity than larger sizes to different cancerous cells [32]. In addition, the effects of PtNPs and their size-specific effects have been recently documented on human epidermal keratinocytes where PtNPs were reported to exhibit higher antimicrobial efficacy than silver NPs [33].

Interestingly, there have been few clinical reports where cutaneous hyperpigmentation was noted in patients subjected to the platinum-based chemotherapeutic cisplatin [34-36]. A combination of PtNPs and palladium NP (PAPLAL) has been approved for use as a cosmetic formulation for stimulating pigmentation in vitiligo patients in Japan [37,38]. In addition, this formulation also exhibited antioxidant capacity by activation of aryl hydrocarbon receptor (AHR) and nuclear factor erythroid-2-related 2 (NRF2) in keratinocytes [39] as well as anti-glycative efficacy [40]. However, the particle size of PtNPs was not reported in this formulation. Furthermore, there has been no study yet on the effects of PtNPs on melanogenesis in melanocyte cell model and how primary particle-size might modulate melanogenesis. A previous study which established the catechol oxidase-mimicking activity of PtNPs (with small sizes exhibiting higher catalytic activity) in a cell-free system, via conversion of L-DOPA to o-quinone, a critical pathway for the synthesis of melanin [41], prompted us to explore if exposure to PtNPs of different sizes might stimulate melanogenesis in melanocyte cell cultures. We hypothesized that SPtNPs will exhibit a higher efficacy than LPtNPs in the stimulation of melanogenesis. Hence, in this study, we have investigated the effects of PtNPs of two different primary particle sizes (SPtNP: $5 \mathrm{~nm}$; LPtNP: $50 \mathrm{~nm}$ ) on melanogenesis in human melanocytes using MNT-1 human melanoma cells and we have validated our results in normal human epidermal melanocytes. 


\section{Materials and Methods}

\subsection{Materials}

Citrate-capped PtNPs of two particle sizes: $5 \mathrm{~nm}$ and $50 \mathrm{~nm}$ (BioPure, sterile, endotoxin-free) were purchased from NanoComposix (San Diego, CA, USA) at a concentration of $1 \mathrm{mg} / \mathrm{mL}$ and were stored at $4{ }^{\circ} \mathrm{C}$ in the dark until use. L-DOPA substrate was purchased from Sigma-Aldrich (St. Louis, MO, USA). Alamar blue reagent (Cat\#: DAL1025) and DCFH-DA (2'-7'dichlorofluorescin diacetate) was purchased from Molecular Probes (Invitrogen, CA, USA).

\subsection{Transmission Electron Microscopy (TEM)}

The primary particle size and morphology of PtNPs were verified using TEM. Briefly, an aliquot of sonicated suspensions of SPtNP and LPtNP were added on copper-coated formvar grids (Ted Pella, Inc., Redding, CA, USA) and imaged using a Tecnai Bio Twin G TEM (FEI, Hillsboro, OR, USA) at 80 kV.

\subsection{Cell Culture}

MNT-1 cells (graciously provided by Dr. Michael Marks, University of Pennsylvania) were cultured using Dulbecco's Modified Eagle Medium (DMEM) medium supplemented with 18\% heat-inactivated fetal bovine serum (HI-FBS; Atlanta Biologicals), 10\% AIM V ${ }^{\circledR}$ medium (Gibco), 1\% MEM non-essential amino acid mixture (Gibco), and 1\% penicillin-streptomycin. Human primary melanocytes derived from moderately-pigmented neonatal skin (HEMn-MP) were purchased from Cascade Biologics (Portland, OR, USA) and cultured in Medium 254 supplemented with human melanocyte growth supplement (HMGS). TrypLE Express (0.05\%; Gibco) was used to detach cells for various assays. All cells were cultured in a humidified incubator $\left(95 \%\right.$ air) at $37^{\circ} \mathrm{C}$ in $5 \% \mathrm{CO}_{2}$.

\subsection{Cytotoxicity Assay}

We first tested different concentrations $(6.25,12.5$ and $25 \mu \mathrm{g} / \mathrm{mL})$ of both PtNPs for cytotoxicity using Alamar Blue assay to identify nontoxic concentration in order to exclude any changes in melanin levels due to cytotoxicity. Alamar blue is a resazurin indicator which is reduced to highly fluorescent pink resorufin in metabolically live cells. Briefly, MNT-1 cells were seeded at $1.5 \times 10^{3}$ cells/well in $0.2 \mathrm{~mL}$ complete medium in black 96-well plates and cultured for $48 \mathrm{~h}$, after which PtNPs (bath sonicated) were added at various concentrations $(6.25,12.5$ and $25 \mu \mathrm{g} / \mathrm{mL})$ and incubated for $72 \mathrm{~h}$. Alamar Blue was added and incubated for $3 \mathrm{~h}$ and fluorescence read at 570/585 nm using a Gemini EM microplate reader (Molecular Devices, San Jose, CA, USA). Cell viability was calculated from relative fluorescence units (RFU) values relative to control groups and expressed in percentage (\%).

\subsection{Melanogenesis Assay in MNT-1 Cells}

MNT-1 cells $\left(1.4 \times 10^{5}\right.$ cells/well $)$ were seeded in 12-well plates and incubated for $24 \mathrm{~h}$ followed by replacement of the culture medium with fresh medium containing different concentrations of SPtNP and LPtNP and incubated for another $72 \mathrm{~h}$. At the end of treatments, the culture medium was centrifuged, aliquoted to a 96-well plate and the absorbance was read at $475 \mathrm{~nm}$ to evaluate extracellular melanin. For evaluation of intracellular melanin, the cells remaining in the wells were harvested, washed in PBS, and solubilized in $\mathrm{NaOH}$ at $70^{\circ} \mathrm{C}$. Next, the lysates were aliquoted, and absorbance was read at $475 \mathrm{~nm}$ using a microplate reader (Versamax ${ }^{\circledR}$, Molecular Devices, San Jose, CA, USA). A portion of the lysate was used to quantify total protein content using BCA reagent (Pierce BCA kit). The absorbance was normalized to the total protein content and expressed as \% of untreated control for both intracellular and extracellular melanin. 


\subsection{Recovery Study of Melanogenesis by PtNPs in MNT-1 Cells}

In order to test whether the effects of PtNPs on melanin synthesis and secretion were reversible, MNT-1 cells $\left(9 \times 10^{4}\right.$ cells/well) were cultured in 12-well plates and treated with NPs for $72 \mathrm{~h}$ (exposure period) followed by culture in PtNPs-free medium for a further $72 \mathrm{~h}$ (recovery period). The intracellular and extracellular melanin levels were measured based on the method outlined earlier.

\subsection{Intracellular Tyrosinase Activity in MNT-1 Cells}

We quantitated the tyrosinase activity in lysates of MNT-1 cells to elucidate the mechanism of stimulation of melanogenesis by PtNPs. MNT-1 cells were cultured in 12-well tissue culture plates at a density of $1.4 \times 10^{5}$ cells/well for $24 \mathrm{~h}$, after which the culture medium was renewed with fresh medium containing PtNPs, and further incubated for $72 \mathrm{~h}$. At the end of treatments, cells were harvested, and cell pellets were washed in PBS and lysed in buffer (containing 1\% NP-40 and protease inhibitors) under ice for $20 \mathrm{~min}$ and then centrifuged to remove cellular debris. Next, $50 \mu \mathrm{L}$ of lysates were aliquoted in a 96-well microplate followed by the addition of $150 \mu \mathrm{L}$ of $3 \mathrm{mM}$ solution of freshly prepared L-DOPA substrate solution was added. Subsequently, the absorbance was measured using the kinetic mode setting at $475 \mathrm{~nm}$ every $30 \mathrm{~s}$ for $30 \mathrm{~min}$ at $30{ }^{\circ} \mathrm{C}$ using a microplate reader. The \% tyrosinase activity was calculated from the slope of the linear range of the velocities after normalization to the total protein content.

\subsection{Intracellular Reactive Oxygen Species (ROS) in MNT-1 Cells}

Intracellular ROS levels was measured using the nonfluorescent $\mathrm{H}_{2} \mathrm{DCFDA}$ ( $2^{\prime}, 7^{\prime}$-Dichlorodihydrofluorescein diacetate) probe which is reduced to fluorescent Dichlorofluorescein (DCF) in the presence of ROS after deacetylation by cellular esterases. MNT- 1 cells $\left(1.2 \times 10^{4}\right.$ cells/well $)$ were plated in a 96-well solid black flat bottom microplate (Corning ${ }^{\circledR}$ ) for $48 \mathrm{~h}$ and further treated with various concentrations of PtNPs for $72 \mathrm{~h}$. After that, cells were washed in HBSS buffer and incubated in $25 \mu \mathrm{M} \mathrm{H}_{2}$ DCFDA probe diluted in DMEM medium (serum free, pyruvate free, phenol-red free) for $45 \mathrm{~min}$ at $37^{\circ} \mathrm{C}$. Post-incubation, the wells were washed in buffer and the plate was read using a fluorescence plate reader at excitation/emission wavelengths of 485/535 nm using well-scan mode (with 9 points /well) and the DCF fluorescence intensity was reported as \% of control.

\subsection{Melanogenesis Assay in HEMn-MP Cells}

HEMn-MP cells $\left(1.6 \times 10^{5}\right.$ cells/well $)$ were seeded in 12-well plate and incubated for $24 \mathrm{~h}$ followed by replacement of medium containing different concentrations of SPtNP and LPtNP and incubated for another $48 \mathrm{~h}$. At the end of treatments, the extracellular melanin and intracellular melanin levels were measured based on the similar method outlined earlier for MNT-1 cells with relative melanin contents normalized to total protein contents and reported as \% of control.

\subsection{Dendricity Measurement in HEMn-MP Cells}

HEMn-MP cells were cultured in 24-well plates at $2 \times 10^{4}$ cells/well for $24 \mathrm{~h}$ followed by the replacement of medium with fresh medium containing PtNPs and maintained for $48 \mathrm{~h}$. At the end of exposure, 5-6 random microscopic fields were imaged at 20× objective magnification using NIS Image analysis software (5.0). The average dendrite length was calculated from the ratio of total dendrite length/number of dendrites; this parameter of dendricity is based on previous report [42].

\subsection{Statistical Analysis}

One-way analysis of variance (ANOVA) with Dunnett's or Tukey's post-hoc test (for comparison between groups) was run using GraphPad Prism software (version 4.0, San Diego, CA, USA). Differences were considered statistically significant at $p<0.05$. All data are reported as Mean \pm SD. 


\section{Results}

\subsection{Characterization of PtNPS}

SPtNP and LPtNP particle sizes were found to be monodispersed based on TEM images (Figure 1A). The other characterization parameters of both NPs (zeta potential, hydrodynamic diameter, surface area) are summarized in Supplementary Materials Table S1.

A

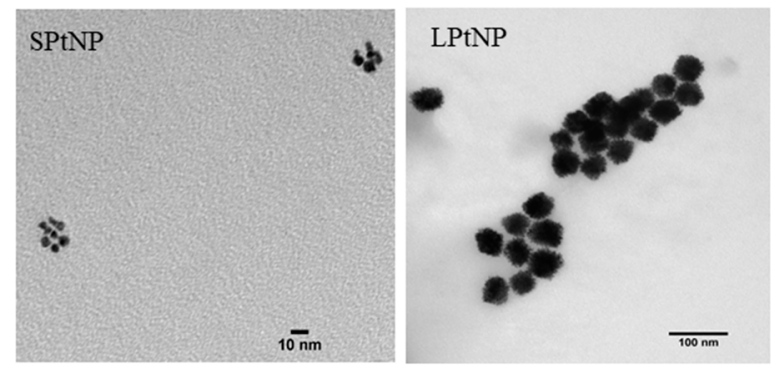

\section{B}

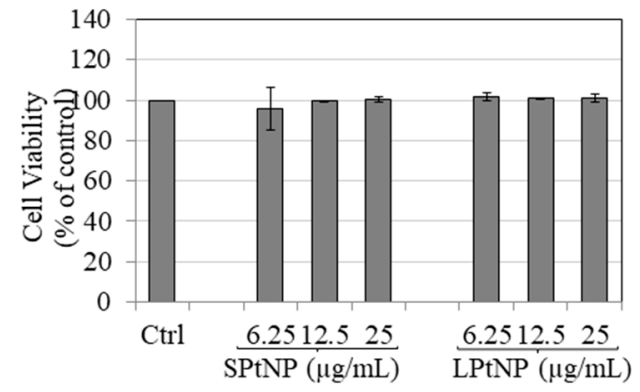

Figure 1. Particle size characterization by TEM for (A) SPtNP and LPtNP; (B) MNT-1 human melanoma cell viability in the presence of different concentrations of SPtNP and LPtNP for $72 \mathrm{~h}$, as measured by Alamar Blue assay; Data are mean \pm SD of at least two independent experiments.

\subsection{Cellular Viability in MNT-1 Cells}

Both SPtNP and LPtNP were nontoxic to MNT-1 cells (Figure 1B) for the duration of $72 \mathrm{~h}$ over the tested concentration ranges $(6.25-25 \mu \mathrm{g} / \mathrm{mL})$. Hence, these concentrations of both NPs were selected for further study on melanogenesis.

\subsection{Cellular Morphology of MNT-1 Cells}

We also examined the MNT-1 cell morphology after treatment with PtNPs to further ascertain nontoxicity. Our results showed that both SPtNP and LPtNP did not affect cell density but induced morphological changes in cells; a higher number of cells treated with SPtNP at $25 \mu \mathrm{g} / \mathrm{mL}$ (Figure 2D) showed elongated dendrites as compared to control (Figure 2A) and compared to LPtNP (Figure 2G). Taken together, these results showed that while both NPs are nontoxic to MNT-1 cells, they induce extension of the dendrites of MNT-1 cells, which was especially evident in SPtNPs.

\subsection{PtNPs Stimulated Extracellular Melanin in MNT-1 Human Melanoma Cells}

We next tested the effects of PtNPs on melanogenesis by assaying intracellular and extracellular melanin levels in MNT-1 cells at nontoxic concentrations of the NPs. Our results demonstrated that SPtNPs significantly increased extracellular melanin dose-dependently by $29.20 \%(p<0.05), 67.64 \%$ $(p<0.01)$ and $91.52 \%(p<0.01)$, at $6.25,12.5$ and $25 \mu \mathrm{g} / \mathrm{mL}$, respectively, as compared to control (Figure 3A). On the other hand, LPtNP showed a significant increase $(p<0.01)$ of $63.24 \%$ only at the highest concentration of $25 \mu \mathrm{g} / \mathrm{mL}$. The increase in extracellular melanin by SPtNP at concentrations of 12.5 and $25 \mu \mathrm{g} / \mathrm{mL}$ was significantly higher than corresponding concentrations of LPtNP. 


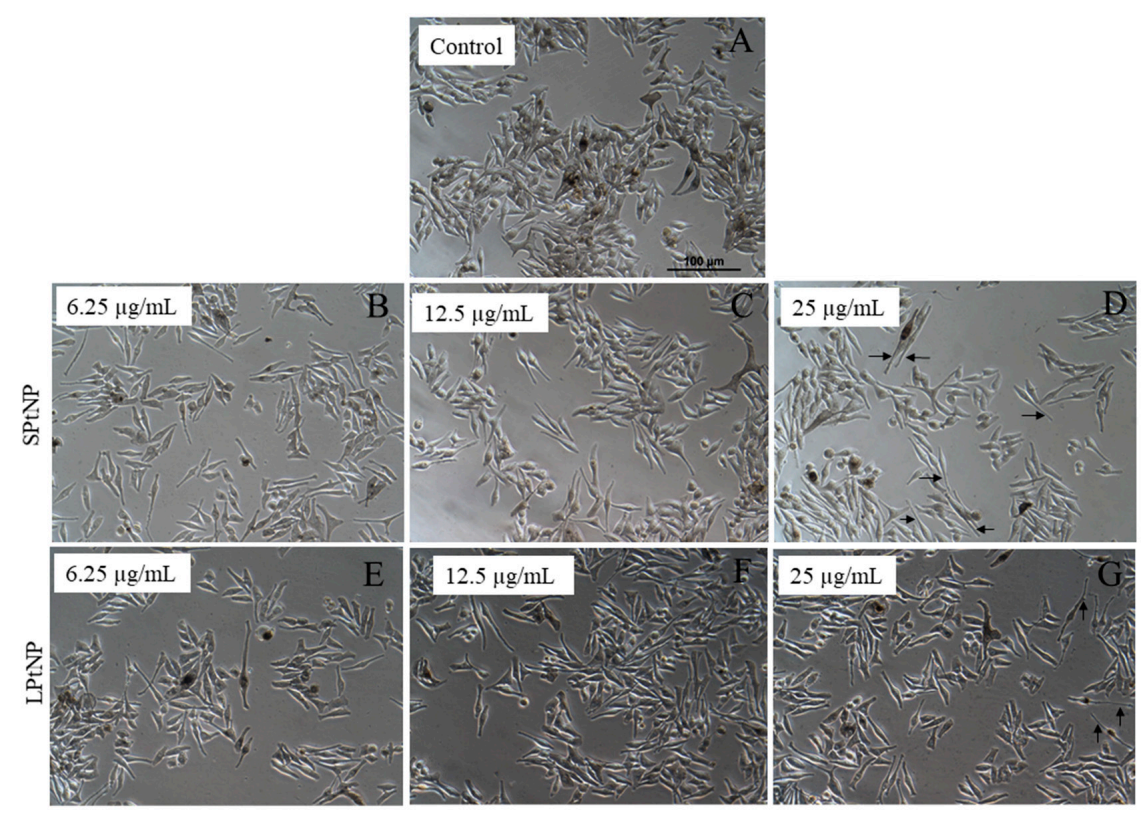

Figure 2. Representative phase-contrast micrographs of (A) MNT-1 human melanoma cells treated with SPtNPs at concentrations (B) $6.25 \mu \mathrm{g} / \mathrm{mL}$; (C) $12.5 \mu \mathrm{g} / \mathrm{mL}$; (D) $25 \mu \mathrm{g} / \mathrm{mL}$ and LPtNPs at concentrations (E) $6.25 \mu \mathrm{g} / \mathrm{mL}$; (F) $12.5 \mu \mathrm{g} / \mathrm{mL}$; (G) $25 \mu \mathrm{g} / \mathrm{mL}$ for a duration of $72 \mathrm{~h}$; black arrows denote the extended dendrites of the cells. Control group did not show extended dendrites; Images were taken at 20x objective magnification.

A

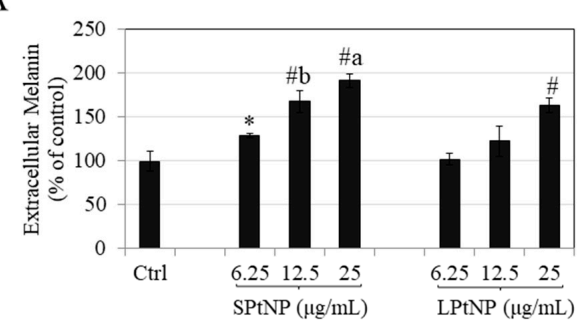

B

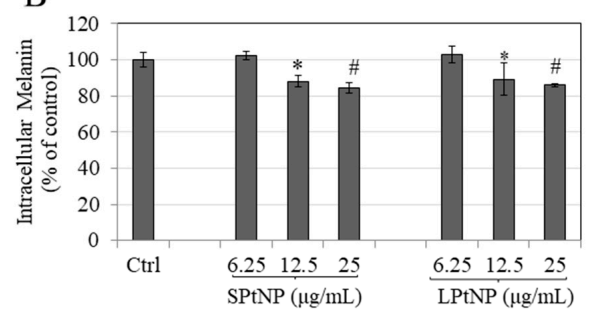

C

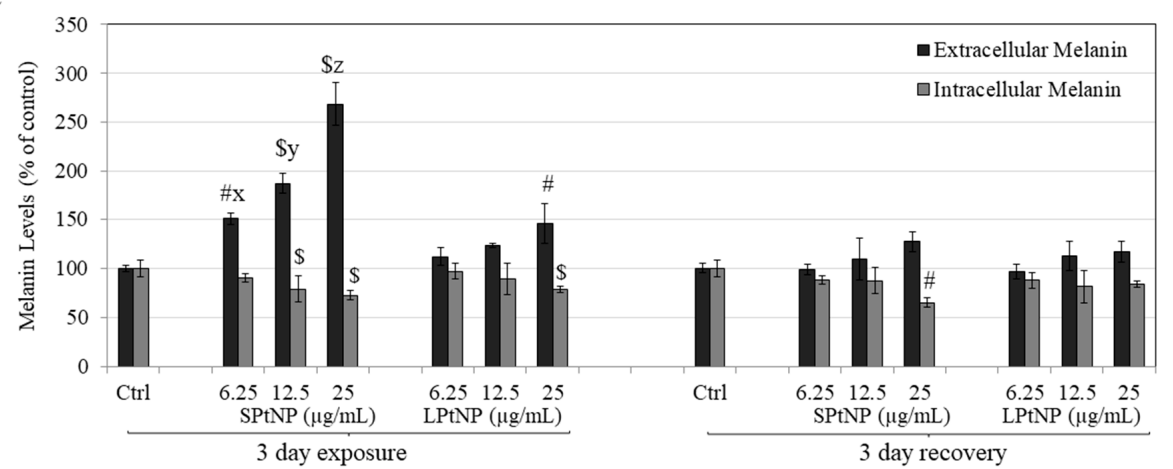

Figure 3. (A) Extracellular and (B) Intracellular melanin levels in cultures of MNT-1 cells treated for $72 \mathrm{~h}$ with different concentrations of SPtNP and LPtNP; (one-way ANOVA followed by Tukey's test: \# $p<0.01$ and ${ }^{*} p<0.05$ versus ctrl; letter $\mathrm{b}-p<0.001$ versus $\operatorname{LPtNP}(12.5 \mu \mathrm{g} / \mathrm{mL})$ and letter $\mathrm{a}-p<0.05$ versus LPtNP $(25 \mu \mathrm{g} / \mathrm{mL}))$; (C) Reversibility of the effects of PtNPs on melanogenesis in MNT-1 cells treated with various concentrations of SPtNP and LPtNP for $72 \mathrm{~h}$ and further cultured in fresh medium without PtNPs for $72 \mathrm{~h} ; \$ p<0.001$ and \# $p<0.01$ versus Ctrl; letter $\mathrm{x}-p<0.05$ versus $\operatorname{LPtNP}(6.25 \mu \mathrm{g} / \mathrm{mL})$, letter $\mathrm{y}-p<0.001$ versus. LPtNP $(12.5 \mu \mathrm{g} / \mathrm{mL})$ and letter $\mathrm{z}-p<0.001$ versus $\operatorname{LPtNP}(25 \mu \mathrm{g} / \mathrm{mL})$; All data are mean \pm SD of three replicates. 
The intracellular melanin levels were significantly reduced for SPtNP by $11.84 \%(p<0.05)$ and $15.48 \%(p<0.01)$ at 12.5 and $25 \mu \mathrm{g} / \mathrm{mL}$, respectively (Figure 3B). For LPtNP, intracellular melanin at 12.5 and $25 \mu \mathrm{g} / \mathrm{mL}$ was reduced by $10.78 \%$ and $14.08 \%$, respectively. Since the levels of extracellular melanin are generally higher than that of intracellular melanin levels, our results indicate that overall, SPtNP stimulates melanin transport. We noted that SPtNP significantly stimulated higher extracellular melanin than corresponding concentrations of LPtNP validating a primary particle-size dependent role on melanosome export.

\subsection{Effects of PtNPs on Reversibility of Melanosome Export in MNT-1 Cells}

Next, we evaluated whether the effects of PtNPs on melanin secretion and synthesis were reversible upon removal of PtNPs from the culture medium. Our results showed that after 3 days of exposure, SPtNP at all concentrations showed a dose-dependent robust increase in extracellular melanin which was significant from control and also higher compared to LPtNP, which was expected based on our earlier results. After washout of PtNPs from the culture medium and continued culture (recovery period), the extracellular melanin levels reverted to control values of the recovery group (Figure 3C), demonstrating that the stimulatory effects of PtNPs on extracellular melanin were reversible and melanosomes resumed their normal function of melanin secretion. However, the intracellular melanin was also recovered for all groups, except SPtNP at highest concentration of $25 \mathrm{ug} / \mathrm{mL}$, where the levels were still significantly lower than recovery control group. Taken together, our results showed that effects of both PtNPs on melanin export were fully reversible.

\subsection{PtNPs Effects on Intracellular Tyrosinase Activity}

We next tested if the stimulatory effects of PtNPs on melanogenesis could be explained, at least in part, by the enhancement of activity of the enzyme tyrosinase in cells. Interestingly, SPtNP did not affect tyrosinase activity at any concentration, while LPtNP showed a significant increase in the tyrosinase activity at $25 \mu \mathrm{g} / \mathrm{mL}$ as compared to control $(p<0.05$; Figure $4 \mathrm{~A})$. These results showed that the mechanism of increased melanogenesis by only LPtNP but not SPtNP, was correlated to intracellular tyrosinase activity.

A

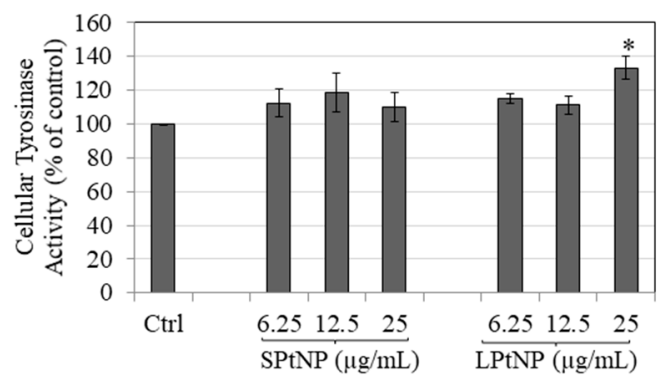

B

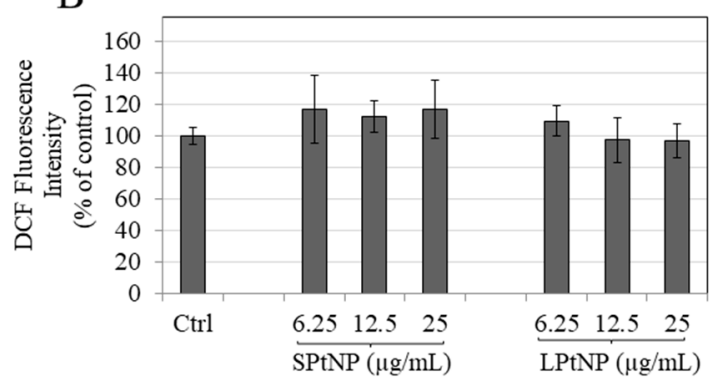

Figure 4. (A) cellular tyrosinase activity in MNT-1 human melanoma cells treated for $72 \mathrm{~h}$ with different concentrations of SPtNP and LPtNP; ( ${ }^{*} p<0.05$; One-way ANOVA with Tukey's post-hoc test); Data are mean \pm SD of at least two independent experiments; (B) intracellular ROS generation measured in MNT-1 cells treated with different concentrations of SPtNP and LPtNP; Data are mean \pm SD of three replicates.

\subsection{Effects of PtNPs on Intracellular Reactive Oxygen Species (ROS) Levels in MNT-1 Cells}

We next tested if the stimulatory effects of PtNPs on melanogenesis could be explained, at least in part, by an increase in the intracellular ROS generation, as melanogenesis is known to be accompanied by increase in ROS levels [43]. Figure 4B summarizes the results on intracellular ROS generation quantified by Dichlorofluorescein (DCF) fluorescence. Both SPtNP and LPtNP did not show any significant effect on the intracellular ROS levels as compared to control. 


\subsection{Effects of PtNPs in HEMn-MP Cells}

To test if the stimulatory capacity of PtNPs on melanin export might be retained in primary human epidermal melanocytes, we next conducted experiments in normal melanocytes derived from moderately pigmented (MP) skin. Both NPs were nontoxic at concentrations of 6.25 and $12.5 \mu \mathrm{g} / \mathrm{mL}$ while SPtNP was toxic at $25 \mu \mathrm{g} / \mathrm{mL}$ hence was excluded from further testing (Figure S1). Both SPtNP and LPtNP demonstrated a significant increase in extracellular melanin as compared to control (Figure 5A). SPtNP showed an increase of $49.48 \%(p<0.001)$ and $84.01 \%(p<0.001)$ at concentrations of 6.25 and $12.5 \mu \mathrm{g} / \mathrm{mL}$, respectively. SPtNP at $12.5 \mu \mathrm{g} / \mathrm{mL}$ showed a significantly higher extracellular melanin $(p<0.01)$ as compared to the lower concentration of $6.25 \mu \mathrm{g} / \mathrm{mL}$. LPtNP showed an increase of $39.8 \%(p<0.01)$ and $42.09 \%(p<0.01)$ at concentrations of 6.25 and $12.5 \mu \mathrm{g} / \mathrm{mL}$, respectively. SPtNP at $12.5 \mu \mathrm{g} / \mathrm{mL}$ showed a significantly higher increase in extracellular melanin levels as compared to LPtNP at $12.5 \mu \mathrm{g} / \mathrm{mL}(p<0.01)$, demonstrating a primary size-specificity in increase of melanin export. Intracellular melanin levels were unaltered for SPtNP at all concentrations; however, we obtained a significant increase of $19.62 \%(p<0.05)$ for LPtNP at $12.5 \mu \mathrm{g} / \mathrm{mL}$ (Figure $5 \mathrm{~B}$ ).

A

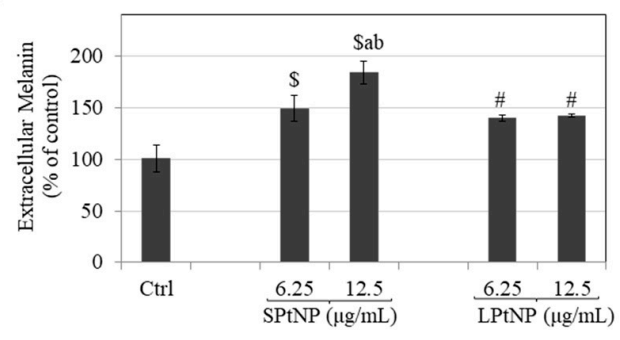

$\mathrm{C}$

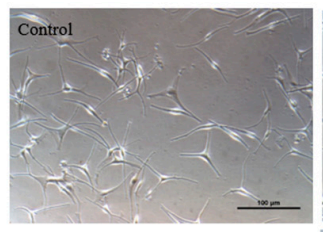

B

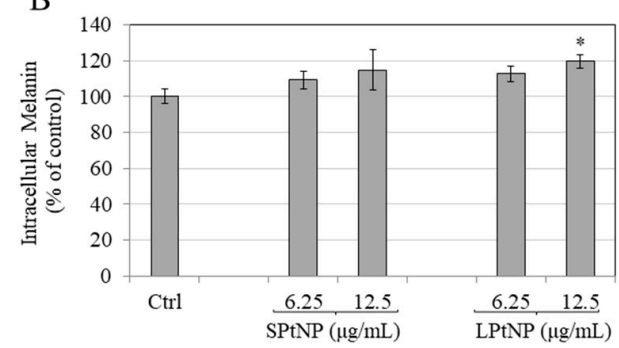

$\mathrm{D}$
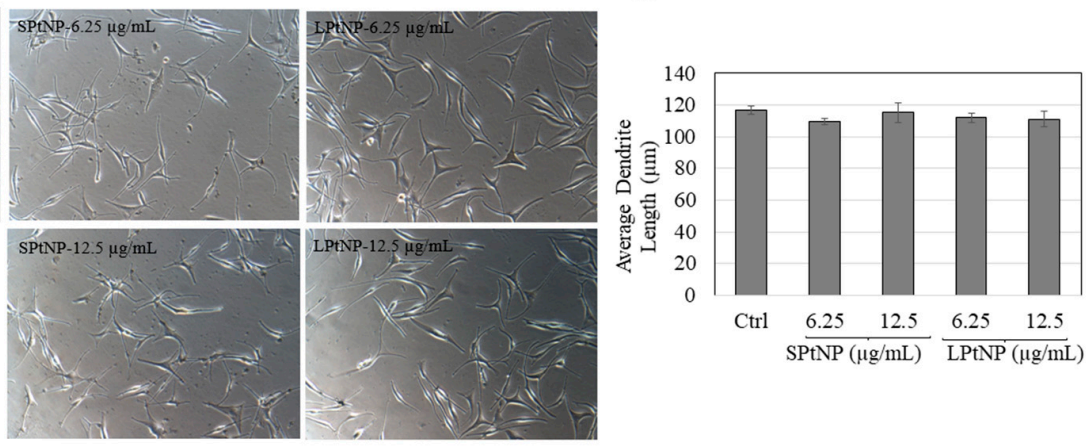

Figure 5. (A) Extracellular and (B) Intracellular melanin levels in human epidermal melanocyte from moderately-pigmented skin (HEMn-MP) treated with different concentrations of SPtNP and LPtNP for $48 \mathrm{~h} ; \$ p<0.001, \# p<0.01$ and ${ }^{*} p<0.05$ versus Ctrl; letter a $-p<0.01$ versus. SPtNP $(6.25 \mu \mathrm{g} / \mathrm{mL})$ and letter $\mathrm{b}-p<0.01$ versus LPtNP $(12.5 \mu \mathrm{g} / \mathrm{mL})$; Data are mean $\pm \mathrm{SD}$ and are combined from at least two independent experiments; (C) Representative phase-contrast photomicrographs showing the morphology of HEMn-MP cells treated with SPtNP and LPtNP over a concentration range $6.25-12.5 \mu \mathrm{g} / \mathrm{mL}$ for $48 \mathrm{~h}$; and quantitation of (D) average dendrite length; Data are mean $\pm \mathrm{SD}$ and is measured from up to 70 cells from triplicate wells for each treatment group.

Taken together, our earlier results of a higher extracellular melanin production by SPtNP as compared to LPtNP in MNT-1 human melanoma cells were also corroborated in primary human melanocytes, establishing the extracellular melanin stimulatory capacity of SPtNP.

\subsection{PtNPs Did Not Alter Dendritic Morphology of HEMn-MP Cells}

Figure 5C summarizes the results of PtNPs on melanocyte morphology where the cells displayed a normal morphology and dendritic network. Quantitation of dendricity showed no change in the 
average dendrite length (Figure 5D) at any concentration of both sizes, suggesting that the capacity of PtNPs to stimulate melanosome secretion is not correlated to alterations in dendricity.

\section{Discussion}

The efficacy of PtNPs in inducing melanin production by catalyzing the oxidation of o-diphenols (catechol-oxidase activity) but not monophenols in a cell-free system with smaller sizes exhibiting a higher catalytic activity was established in an earlier report [41]. Our results in the current study validate those effects in a melanocyte cell model and provide a proof-of-principle for the use of PtNPs for enhancing human melanogenesis. We have also established the superior efficacy of SPtNP as compared to LPtNP, thereby validating a primary particle size-specific effect of these NPs on the enhancement of melanin secretion. To the best of our knowledge, this is the first study to show that PtNPs have a significant impact on melanogenesis in human melanoma cells (MNT-1) and primary human melanocytes (HEMn-MP) by stimulating melanin secretion, with small size nanoparticle (SPtNP) being a better stimulator. An increase in production of melanin pigment is protective for hypopigmentation disorders and also attractive for sunless tanning applications, however, an over-secretion of melanin can cause formation of hyper-pigmentary spots which pose aesthetic concerns and are a risk factor for skin cancer. Hence, we also evaluated if the augmentation of extracellular melanin by PtNPs on melanogenesis could be reversible upon removal of PtNPs from the culture medium to establish safety and our results validate that the effects of PtNPs on the enhancement of melanin export are not permanent.

Although PtNPs have shown excellent antioxidant capacity and attenuated ROS production in previous studies [26,44] while in another report they increased ROS production [45], in the current study, we did not obtain any effects of these NPs on ROS generation inside MNT-1 cells. Our results of tyrosinase activity in MNT-1 cells showed no effect by SPtNPs at any concentration, but a significant increase by LPtNP. This finding showed that the mechanisms by which SPtNP stimulate melanin secretion are distinct from LPtNP and might involve other pathways which remain to be determined. Our results showed that PtNPs were more cytotoxic to HEMn-MP cells than MNT-1 cells as we noted that SPtNP reduced viability of HEMn-MP cells starting from $25 \mu \mathrm{g} / \mathrm{mL}$, but was nontoxic in MNT-1 cells up to higher concentration of $50 \mu \mathrm{g} / \mathrm{mL}$ (data not shown). MNT-1 cells are immortalized melanoma cells which differ biologically from normal human melanocytes. Human melanocytes have a higher oxidative state due to the higher generation of ROS [43] and the increased oxidation of $\mathrm{Pt}^{0}$ to $\mathrm{Pt}^{\mathrm{II}}$ inside them might explain the cytotoxicity of SPtNP at concentrations $>12.5 \mu \mathrm{g} / \mathrm{mL}$ since oxidation levels of cells have been shown to affect the catalytic activity of PtNPs [46]. The presence of serum in culture medium can also influence the physicochemical properties of NPs by altering their cellular effects due to the formation of protein corona [47]. Notably, MNT-1 cells were cultured in serum-containing medium (18\% serum) in contrast to HEMn-MP cells which are routinely cultured in serum-free medium $(0.5 \%$ serum $)$. Hence, the differential effects and cytotoxicity can be attributed, at least in part, to the differences in nanoparticle dispersion, protein corona formation, opsonization and cellular uptake. We speculate that due to smaller size and higher surface area-to-volume ratio of SPtNPs as compared to LPtNP (Supplementary Materials Table S1), they had a higher cellular uptake, which may account for the increased rate of melanin exportation in the cells, although to further ascertain and quantify the cellular uptake, inductively coupled plasma mass spectrometry (ICP-MS) studies of cells treated with both NPs are warranted. There is no study on the formation and the effects of protein corona on PtNPs yet, however they exhibit antimicrobial activity similar to silver NPs which have been well-studied for protein corona formation [48]. Future studies to characterize the formation of protein corona on PtNPs and study of its effects on cytotoxicity and melanogenesis might be interesting, as the particle-size has been reported to play a role in protein corona leading to a differential cellular uptake and activity $[49,50]$. Citrate is a biocompatible coating commonly used for stabilizing metal nanoparticles and did not contribute to the observed increase in extracellular melanin since the PtNPs used were originally suspended in a $2 \mathrm{mM}$ citrate buffer which was further diluted to get the working concentrations used 
in cellular assays. A previous study showed a significant stimulation of melanin secretion only at a higher concentration $(20 \mathrm{mM})$ of citrate in B16F10 mouse melanoma cells [51]. Hence, our results of a higher induction of melanin secretion are ascribed exclusively to PtNPs.

The hydrodynamic size which is the 'secondary' particle size (agglomerate size) after dispersion of citrate-coated PtNPs in cell culture medium will likely alter as shown previously [52,53]. For example, in one study [52], the citrate-coated platinum nanoparticles obtained from same vendor, were tested and the authors showed that the particle sizes of $5 \mathrm{~nm}$ and $70 \mathrm{~nm}$ were increased after suspension in culture medium containing 15\% serum; the hydrodynamic diameters showed a Gaussian distribution reflective of adsorbed serum proteins which can lead to formation of protein corona and agglomeration. Another study [53] also showed that citrate-coated $70 \mathrm{~nm}$ PtNPs had an increased size and the mean value of hydrodynamic size was $112.4 \mathrm{~nm}$ in DMEM medium. Collectively, these results can be used as a reference to gauge the hydrodynamic size of PtNPs used in our study (5 nm, $50 \mathrm{~nm}$ ) since we have not measured hydrodynamic size in MNT-1 and HEMn-MP culture mediums in this study due to few limitations. Out of the aforementioned studies, one of them conducted dynamic light scattering (DLS) after 5 min incubation [52], while the other [53] did not report the incubation duration. It should be emphasized that factors such as NP concentration and incubation time with culture medium can also have an effect on the DLS particle size distribution results and difficulties in reproducibility of particle size distribution has also been noted [54] due to complex media composition which can also affect the results [55]. Hence, due to such disparities in protocols, we have only focused on primary particle sizes. Although, the information of hydrodynamic size of both nanoparticles after suspension in cell culture medium of both cell lines would have added value to our study, we believe that our results can be still attributed to differences in 'primary' particle sizes.

Previous reports have dissected the effects of ionic and particulate forms of PtNPs on the modulation of biological activities. A recent study conducted with fish cells compared PtNPs and Pt ions and concluded that Pt ions elicited similar cytotoxicity as PtNPs [56]. Gehrke et al. [57] comprehensively studied the effects of Pt ions after sedimenting the NPs by ultracentrifugation and using the supernatant to analyze the concentrations of soluble Pt species by ICP-MS. The authors further demonstrated that while the amount of $\mathrm{Pt}$ ions released from PtNPs into the culture medium was minimal, but after uptake into cellular endosomes, these PtNPs released sufficient amounts of Pt ions due to the low endosomal $\mathrm{pH}$ and hydrolytic enzymes; these ionic species were responsible for the induction of DNA damage and cytotoxicity. In another study, the authors reported that the amount of dissolution of ionic species from PtNPs was minimal in the culture medium, possibly due to the formation of protein corona [53]. We did not dissect the role of PtNPs vs. Pt ions as it was beyond the scope of the present study and was not the primary focus; however, studies where the amount of $\mathrm{Pt}$ ions in the culture medium and in the cells are quantitated using ICP-MS are warranted in future.

Several lines of evidence suggest that an increased export of melanosomes is linked to an increase in cell dendricity as by increasing dendrite length, the cell can make contact with multiple keratinocytes [58,59]. Although we qualitatively observed elongated dendrites in MNT-1 cells treated with PtNPs, there was no change in dendrite morphology quantified by average dendrite length in HEMn-MP cells. The differences could be related to the different dendritic morphology of both cells since HEMn-MP melanocyte possess multiple dendrites (ranging from 3-6) which extend few hundreds of microns whereas MNT-1 cells are bidendritic and their dendrite length is usually a few microns in length. Although MNT-1 cells lack the morphological dendritic network as present in HEMn-MP, for melanin export they offer an advantage over primary human melanocytes and do not exhibit donor-dependent variation.

We have also evaluated the effects of PtNPs using a coculture model of HEMn-MP cells with human keratinocytes; this coculture mode is more representative of the in vivo situation where melanocytes are in close contact with keratinocytes. Both SPtNP and LPtNP were tested at $12.5 \mu \mathrm{g} / \mathrm{mL}$ as this concentration showed the most potent effects in monoculture. The nontoxicity of both NPs at this concentration to $\mathrm{HaCaT}$ cells was assessed before conducting cocultures (Supplementary 
Materials Figure S2). SPtNP showed a significant increase in extracellular melanin as compared to control, which was significantly higher compared to LPtNP (Supplementary Materials Figure S3A) which indicates that PtNPs might stimulate the release of soluble factors from keratinocytes in coculture which might, in turn, increase the secretion of melanosomes, however, this hypothesis warrants further testing. Interestingly, we also obtained higher intracellular melanin in HEMn-MP cocultures treated with SPtNPs as compared to LPtNPs, which might be ascribed to the presence of keratinocytes (Supplementary Materials Figure S3B). Keratinocyte-derived soluble factors have shown to be pro-melanogenic and increase melanin synthesis [60]. Additionally, the ratio of melanocytes to keratinocytes is 1:36 in epidermis in vivo, hence our results which were based on a coculture ratio of 1:2 need to be interpreted with caution. Nevertheless, our ratio is closer to the ratio of melanocytes and keratinocytes in the hair bulb where the ratio is 1:1 in the basal layer close to dermal papilla, and it is $1: 5$ in the whole hair bulb [61,62].

Although soluble platinum compounds have been shown to induce dermal irritancy or sensitization [63], there is no evidence of skin sensitizing potential of PtNPs to date [64]. Additionally, the PAPLAL formulation developed for the treatment of vitiligo, described that the incorporation of PtNPs actually aided in reducing the sensitization and inflammatory effects of palladium NPs [65]. Based on these lines of evidence, we believe that SPtNPs can be used for enhancing melanin pigmentation without any safety concern, although more in-depth studies of safety and toxicology will be necessary in future. Furthermore, since our results reflect the effects of PtNPs in human melanocytes derived from moderately-pigmented skin, which is representative of Asian skin, whether PtNPs can exhibit similar effects in the absence of cytotoxicity in lightly-pigmented melanocytes (Caucasian skin) remains to be determined in future studies. Although we have focused on epidermal melanocytes in the present study, our results suggest that it would be interesting to further explore the effects of PtNPs using in vitro cultured hair follicles to evaluate if they might exhibit stimulating effects on follicular melanogenesis. Several studies have reported on the biogenic synthesis of PtNPs which have been carried out with plant-based extracts [66,67]. Although, the PtNPs tested in current study were chemically synthesized with citrate-stabilized coating, the future prospect of synthesis of biogenic PtNPs will provide a further appeal to the capacity of melanogenesis enhancement and provide advantages in terms of being natural for green cosmetics.

\section{Conclusions}

In summary, our results demonstrate the potential efficacy of citrate-capped PtNPs as a melanogenesis enhancer in both immortalized and primary human melanocyte cells, with SPtNP demonstrating a higher efficacy than LPtNP indicating a primary particle size-specific effect on melanosome export. Future studies to evaluate the melanogenesis stimulatory activity of SPtNP in vivo and further elucidation of mechanisms of stimulation of melanogenesis are warranted. SPtNP thus warrants further investigation in clinical studies to be potentially considered for treating uneven skin hypopigmentation disorders and for sunless tanning and might also find application in grey hair repigmentation.

Supplementary Materials: Supplementary materials can be found at http://www.mdpi.com/2079-9284/7/4/88/s1. Table S1: Physicochemical characterization of SPtNP and LPtNP as provided by the manufacturer. Figure S1: Viability of HEMn-MP cells treated with different concentrations $(6.25-25 \mu \mathrm{g} / \mathrm{mL})$ of SPtNP and LPtNP for $48 \mathrm{~h}$, evaluated by Alamar Blue assay; Data is mean \pm SD of triplicate determinations. Figure S2: Viability of HaCaT cells treated with different concentrations $(6.25-25 \mu \mathrm{g} / \mathrm{mL})$ of SPtNP and LPtNP for $72 \mathrm{~h}$, evaluated by Alamar Blue assay; Data is Mean \pm SD of triplicate determinations. Figure S3: Melanin assay with (A) Extracellular and; (B) Intracellular levels in cocultures of HEMn-MP an HaCaT cells treated with SPtNP and LPtNP at $12.5 \mu \mathrm{g} / \mathrm{mL}$; $\left(\$ p<0.001\right.$ and ${ }^{*} p<0.05$ versus Ctrl; letter $\mathrm{a}-p<0.01$ versus $\mathrm{LPtNP}$, letter $\mathrm{b}-p<0.01$ versus LPtNP; Data is Mean \pm SD of triplicates [68].

Author Contributions: S.G. conceptualized the idea of the use of PtNPs for melanogenesis, planned, organized, and conducted all experiments and wrote the manuscript. J.T. contributed technical inputs related with the characterization of nanoparticles and skin applications and reviewed the manuscript. All authors have read and agreed to the published version of the manuscript. 
Funding: The authors received no specific funding for the research, authorship, and/or publication of this article.

Acknowledgments: We would like to acknowledge Michael Marks (University of Pennsylvania) for providing MNT-1 cells and Sanford R. Simon (Stony Brook University) for the use of resources. The current work is an extension of the work presented at the 42nd Annual Northeast Bioengineering Conference (NEBEC) held in Binghamton University, USA in 2017.

Conflicts of Interest: The authors declare no conflict of interest.

\section{Abbreviations}

$\begin{array}{ll}\text { L-DOPA } & \text { L-3,4 dihydroxyphenylalanine } \\ \text { DMEM } & \text { Dulbecco's Modified Eagle Medium } \\ \text { HMGS } & \text { Human Melanocyte Growth Supplement } \\ \text { HEM } & \text { Human-Epidermal Melanocytes } \\ \text { MP } & \text { Moderately Pigmented } \\ \text { TEM } & \text { Transmission Electron Microscopy } \\ \text { PtNPs } & \text { Platinum Nanoparticles } \\ \text { SPtNP } & \text { Small Platinum Nanoparticles } \\ \text { LPtNP } & \text { Large Platinum Nanoparticles } \\ \text { ANOVA } & \text { Analysis of Variance } \\ \text { HBSS } & \text { Hank's Balanced Salt Solution } \\ \text { ROS } & \text { Reactive Oxygen Species } \\ \text { DCF } & \text { Dichlorofluorescein }\end{array}$

\section{References}

1. Fernandez-Flores, A.; Saeb-Lima, M.; Cassarino, D.S. Histopathology of Aging of The Hair Follicle. J. Cutan. Pathol. 2019, 46, 508-519. [CrossRef] [PubMed]

2. Maranduca, M.A.; Branisteanu, D.; Serban, D.N.; Branisteanu, D.C.; Stoleriu, G.; Manolache, N.; Serban, I.L. Synthesis and Physiological Implications of Melanic Pigments. Oncol. Lett. 2019, 17, 4183-4187. [CrossRef] [PubMed]

3. Riley, P.A. Melanogenesis and Melanoma. Pigment Cell Res. 2003, 16, 548-552. [CrossRef] [PubMed]

4. D'orazio, J.; Jarrett, S.; Amaro-Ortiz, A.; Scott, T. Uv Radiation and the Skin. Int. J. Mol. Sci. 2013, 14, 12222-12248. [CrossRef] [PubMed]

5. Hearing, V.J. Determination of Melanin Synthetic Pathways. J. Investig. Dermatol. 2011, 131, E8-E11. [CrossRef]

6. Fitzpatrick, T.B.; Breathnach, A. The Epidermal Melanin Unit System. Dermatol. Wochenschr. 1963, 147, 481. [PubMed]

7. Hirobe, T. Structure and Function of Melanocytes: Microscopic Morphology and Cell Biology of Mouse Melanocytes in The Epidermis and Hair Follicle. Histol. Histopathol. 1995, 10, 223-237. [PubMed]

8. Dutta, S.; Panda, S.; Singh, P.; Tawde, S.; Mishra, M.; Andhale, V.; Athavale, A.; Keswani, S.M. Hypopigmentation in Burns Is Associated with Alterations in the Architecture of the Skin and the Dendricity of The Melanocytes. Burns 2020, 46, 906-917. [CrossRef] [PubMed]

9. Ando, H.; Niki, Y.; Ito, M.; Akiyama, K.; Matsui, M.S.; Yarosh, D.B.; Ichihashi, M. Melanosomes Are Transferred from Melanocytes to Keratinocytes Through the Processes of Packaging, Release, Uptake, and Dispersion. J. Investig. Dermatol. 2012, 132, 1222-1229. [CrossRef]

10. Petersen, A.B.; Wulf, H.C.; Gniadecki, R.; Gajkowska, B. Dihydroxyacetone, The Active Browning Ingredient in Sunless Tanning Lotions, Induces Dna Damage, Cell-Cycle Block and Apoptosis in Cultured Hacat Keratinocytes. Mutat. Res. 2004, 560, 173-186. [CrossRef]

11. Levine, J.A.; Sorace, M.; Spencer, J.; Siegel, D.M. The Indoor Uv Tanning Industry: A Review of Skin Cancer Risk, Health Benefit Claims, and Regulation. J. Am. Acad. Derm. 2005, 53, 1038-1044. [CrossRef]

12. Pawelek, J.M. Approaches to Increasing Skin Melanin with Msh Analogs and Synthetic Melanins. Pigment Cell Res. 2001, 14, 155-160. [CrossRef] [PubMed]

13. Abdel-Malek, Z.; Swope, V.B.; Suzuki, I.; Akcali, C.; Harriger, M.D.; Boyce, S.T.; Urabe, K.; Hearing, V.J. Mitogenic and Melanogenic Stimulation of Normal Human Melanocytes by Melanotropic Peptides. Proc. Natl. Acad. Sci. USA 1995, 92, 1789-1793. [CrossRef] [PubMed] 
14. Fytianos, G.; Rahdar, A.; Kyzas, G.Z. Nanomaterials in Cosmetics: Recent Updates. Nanomaterials 2020, 10, 979. [CrossRef] [PubMed]

15. Aziz, Z.A.A.; Mohd-Nasir, H.; Ahmad, A.; Mohd Setapar, S.H.; Peng, W.L.; Chuo, S.C.; Khatoon, A.; Umar, K.; Yaqoob, A.A.; Mohamad Ibrahim, M.N. Role of Nanotechnology for Design and Development of Cosmeceutical: Application In Makeup and Skin Care. Front. Chem. 2019, 7, 739. [CrossRef]

16. Bilal, M.; Iqbal, H. New Insights on Unique Features and Role of Nanostructured Materials in Cosmetics. Cosmetics 2020, 7, 24. [CrossRef]

17. Rigano, L.; Lionetti, N. Nanobiomaterials In Galenic Formulations and Cosmetics. In Nanobiomaterials in Galenic Formulations and Cosmetics; Elsevier: Amsterdam, The Netherlands, 2016; pp. 121-148.

18. Kockler, J.; Oelgemöller, M.; Robertson, S.; Glass, B.D. Influence of Titanium Dioxide Particle Size on the Photostability of the Chemical Uv-Filters Butyl Methoxy Dibenzoylmethane and Octocrylene in a Microemulsion. Cosmetics 2014, 1, 128-139. [CrossRef]

19. Haddada, M.B.; Gerometta, E.; Chawech, R.; Sorres, J.; Bialecki, A.; Pesnel, S.; Spadavecchia, J.; Morel, A.-L. Assessment of Antioxidant and Dermoprotective Activities of Gold Nanoparticles as Safe Cosmetic Ingredient. Colloids Surf. B Biointerfaces 2020, 189, 110855. [CrossRef]

20. Gajbhiye, S.; Sakharwade, S. Silver Nanoparticles in Cosmetics. J. Cosmet. Dermatol. Sci. Appl. 2016, 6, 48-53. [CrossRef]

21. Yamada, M.; Foote, M.; Prow, T.W. Therapeutic Gold, Silver, and Platinum Nanoparticles. Wiley Interdiscip. Rev. Nanomed. Nanobiotechnol. 2015, 7, 428-445. [CrossRef]

22. Choosing Platinum Skin Care. Available online: https://bionyxskincare.com/choosing-platinum-skincare/ (accessed on 6 September 2020).

23. Pedone, D.; Moglianetti, M.; De Luca, E.; Bardi, G.; Pompa, P.P. Platinum Nanoparticles in Nanobiomedicine. Chem. Soc. Rev. 2017, 46, 4951-4975. [CrossRef]

24. Yoshihisa, Y.; Honda, A.; Zhao, Q.L.; Makino, T.; Abe, R.; Matsui, K.; Shimizu, H.; Miyamoto, Y.; Kondo, T.; Shimizu, T. Protective Effects of Platinum Nanoparticles Against Uv-Light-Induced Epidermal Inflammation. Exp. Dermatol. 2010, 19, 1000-1006. [CrossRef]

25. Gatto, F.; Moglianetti, M.; Pompa, P.P.; Bardi, G. Platinum Nanoparticles Decrease Reactive Oxygen Species and Modulate Gene Expression without Alteration of Immune Responses in Thp-1 Monocytes. Nanomaterials 2018, 8, 392. [CrossRef]

26. Kajita, M.; Hikosaka, K.; Iitsuka, M.; Kanayama, A.; Toshima, N.; Miyamoto, Y. Platinum Nanoparticle Is a Useful Scavenger of Superoxide Anion and Hydrogen Peroxide. Free Radic. Res. 2007, 41, 615-626. [CrossRef] [PubMed]

27. Moglianetti, M.; De Luca, E.; Pedone, D.; Marotta, R.; Catelani, T.; Sartori, B.; Amenitsch, H.; Retta, S.F.; Pompa, P.P. Platinum Nanozymes Recover Cellular Ros Homeostasis in an Oxidative Stress-Mediated Disease Model. Nanoscale 2016, 8, 3739-3752. [CrossRef]

28. Yusof, F.; Ismail, N.A.S. Antioxidants Effects of Platinum Nanoparticles: A Potential Alternative Treatment to Lung Diseases. J. Appl. Pharm. Sci. 2015, 5. [CrossRef]

29. Katsumi, H.; Fukui, K.; Sato, K.; Maruyama, S.; Yamashita, S.; Mizumoto, E.; Kusamori, K.; Oyama, M.; Sano, M.; Sakane, T. Pharmacokinetics and Preventive Effects of Platinum Nanoparticles as Reactive Oxygen Species Scavengers on Hepatic Ischemia/Reperfusion Injury In Mice. Met. Integr. Biometal Sci. 2014, 6, 1050-1056. [CrossRef]

30. Tuncer, S.; Colakoglu, M.; Ulusan, S.; Ertas, G.; Karasu, C.; Banerjee, S. Evaluation of Colloidal Platinum on Cytotoxicity, Oxidative Stress and Barrier Permeability Across the Gut Epithelium. Heliyon 2019, 5, E01336. [CrossRef]

31. Depciuch, J.; Stec, M.; Klebowski, B.; Maximenko, A.; Drzymala, E.; Baran, J.; Parlinska-Wojtan, M. Size Effect of Platinum Nanoparticles in Simulated Anticancer Photothermal Therapy. Photodiagn. Photodyn. 2020, 29, 101594. [CrossRef]

32. Buchtelova, H.; Dostalova, S.; Michalek, P.; Krizkova, S.; Strmiska, V.; Kopel, P.; Hynek, D.; Richtera, L.; Ridoskova, A.; Adam, P.; et al. Size-Related Cytotoxicological Aspects of Polyvinylpyrrolidone-Capped Platinum Nanoparticles. Food Chem. Toxicol. 2017, 105, 337-346. [CrossRef]

33. Konieczny, P.; Goralczyk, A.G.; Szmyd, R.; Skalniak, L.; Koziel, J.; Filon, F.L.; Crosera, M.; Cierniak, A.; Zuba-Surma, E.K.; Borowczyk, J. Effects Triggered by Platinum Nanoparticles on Primary Keratinocytes. Int. J. Nanomed. 2013, 8, 3963. 
34. Kim, K.J.; Chang, S.E.; Choi, J.H.; Sung, K.J.; Moon, K.C.; Koh, J.K. Periungal Hyperpigmentation Induced by Cisplatin. Clin. Exp. Dermatol. 2002, 27, 118-119. [CrossRef] [PubMed]

35. Noori, M.; Hunter-Ellul, L.; Kelly, B. Serpentine Supravenous Hyperpigmentation Following Cisplatin and Pemetrexed Chemotherapy. Cutis 2017, 99, E20-E22.

36. Al-Lamki, Z.; Pearson, P.; Jaffe, N. Localized Cisplatin Hyperpigmentation Induced by Pressure. A Case Report. Cancer 1996, 77, 1578-1581. [CrossRef]

37. Shibuya, S.; Ozawa, Y.; Watanabe, K.; Izuo, N.; Toda, T.; Yokote, K.; Shimizu, T. Palladium and Platinum Nanoparticles Attenuate Aging-Like Skin Atrophy Via Antioxidant Activity in Mice. PLoS ONE 2014, 9, E109288. [CrossRef] [PubMed]

38. Shibata, T.; Yoshikawa, R.; Ichihashi, M. The Novel Therapy for Vitiligo Vulgaris: Topical Use of Cosmetic Cream of Platinum Nanoparticles and Palladium Nanoparticles Which Show Strong Catalase-Like Activity. J. Pigment. Disord. 2015, 2. [CrossRef]

39. Tsuji, G.; Hashimoto-Hachiya, A.; Takemura, M.; Kanemaru, T.; Ichihashi, M.; Furue, M. Palladium and Platinum Nanoparticles Activate Ahr and Nrf2 In Human Keratinocytes-Implications In Vitiligo Therapy. J. Investig. Dermatol. 2017, 137, 1582-1586. [CrossRef]

40. Takabe, W.; Yagi, M.; Ichihashi, M.; Yonei, Y. Anti-Glycative Effect of Palladium and Platinum Nanoparticle Solution. Glycative Stress Res. 2016, 3, 222-228.

41. Liu, Y.; Wu, H.; Chong, Y.; Wamer, W.G.; Xia, Q.; Cai, L.; Nie, Z.; Fu, P.P.; Yin, J.-J. Platinum Nanoparticles: Efficient and Stable Catechol Oxidase Mimetics. ACS Appl. Mater. Interfaces 2015, 7, 19709-19717. [CrossRef]

42. Sirimahachaiyakul, P.; Sood, R.F.; Muffley, L.A.; Seaton, M.; Lin, C.-T.; Qiao, L.; Armaly, J.S.; Hocking, A.M.; Gibran, N.S. Race Does Not Predict Melanocyte Heterogeneous Responses To Dermal Fibroblast-Derived Mediators. PLoS ONE 2015, 10, E0139135. [CrossRef]

43. Denat, L.; Kadekaro, A.L.; Marrot, L.; Leachman, S.A.; Abdel-Malek, Z.A. Melanocytes As Instigators and Victims of Oxidative Stress. J. Investig. Dermatol. 2014, 134, 1512-1518. [CrossRef]

44. Watanabe, A.; Kajita, M.; Kim, J.; Kanayama, A.; Takahashi, K.; Mashino, T.; Miyamoto, Y. In Vitro Free Radical Scavenging Activity of Platinum Nanoparticles. Nanotechnology 2009, 20, 455105. [CrossRef]

45. Asharani, P.V.; Xinyi, N.; Hande, M.P.; Valiyaveettil, S. Dna Damage and P53-Mediated Growth Arrest In Human Cells Treated With Platinum Nanoparticles. Nanomedicine 2010, 5, 51-64. [CrossRef]

46. Shoshan, M.S.; Vonderach, T.; Hattendorf, B.; Wennemers, H. Peptide-Coated Platinum Nanoparticles With Selective Toxicity Against Liver Cancer Cells. Angew. Chem. Int. Ed. Engl. 2019, 58, 4901-4905. [CrossRef]

47. Monopoli, M.P.; Aberg, C.; Salvati, A.; Dawson, K.A. Biomolecular Coronas Provide the Biological Identity of Nanosized Materials. Nat. Nanotechnol. 2012, 7, 779-786. [CrossRef] [PubMed]

48. Juling, S.; Niedzwiecka, A.; Bóhmert, L.; Lichtenstein, D.; Selve, S.R.; Braeuning, A.; Thünemann, A.F.; Krause, E.; Lampen, A. Protein Corona Analysis of Silver Nanoparticles Links to Their Cellular Effects. J. Proteome Res. 2017, 16, 4020-4034. [CrossRef]

49. Lundqvist, M.; Stigler, J.; Elia, G.; Lynch, I.; Cedervall, T.; Dawson, K.A. Nanoparticle Size and Surface Properties Determine the Protein Corona with Possible Implications For Biological Impacts. Proc. Natl. Acad. Sci. USA 2008, 105, 14265-14270. [CrossRef]

50. Tenzer, S.; Docter, D.; Rosfa, S.; Wlodarski, A.; Kuharev, J.R.; Rekik, A.; Knauer, S.K.; Bantz, C.; Nawroth, T.; Bier, C. Nanoparticle Size Is A Critical Physicochemical Determinant of the Human Blood Plasma Corona: A Comprehensive Quantitative Proteomic Analysis. ACS Nano 2011, 5, 7155-7167. [CrossRef]

51. Bhatnagar, V.; Srirangam, A.; Abburi, R. In Vitro Modulation of Proliferation and Melanization of Melanoma Cells by Citrate. Mol. Cell. Biochem. 1998, 187, 57-65. [CrossRef]

52. Lin, C.-X.; Gu, J.-L.; Cao, J.-M. The Acute Toxic Effects of Platinum Nanoparticles on Ion Channels, Transmembrane Potentials of Cardiomyocytes In Vitro and Heart Rhythm In Vivo In Mice. Int. J. Nanomed. 2019, 14, 5595. [CrossRef]

53. Labrador-Rached, C.J.; Browning, R.T.; Braydich-Stolle, L.K.; Comfort, K.K. Toxicological Implications of Platinum Nanoparticle Exposure: Stimulation of Intracellular Stress, Inflammatory Response, and Akt Signaling In Vitro. J. Toxicol. 2018, 2018, 1367801. [CrossRef]

54. Gollwitzer, C.; Bartczak, D.; Goenaga-Infante, H.; Kestens, V.; Krumrey, M.; Minelli, C.; Pálmai, M.; Ramaye, Y.; Roebben, G.; Sikora, A. A Comparison of Techniques for Size Measurement of Nanoparticles In Cell Culture Medium. Anal. Methods 2016, 8, 5272-5282. [CrossRef] 
55. Marucco, A.; Aldieri, E.; Leinardi, R.; Bergamaschi, E.; Riganti, C.; Fenoglio, I. Applicability and Limitations in the Characterization of Poly-Dispersed Engineered Nanomaterials In Cell Media By Dynamic Light Scattering (Dls). Materials 2019, 12, 3833. [CrossRef]

56. Demir, V.; Bucher, J.; Kropf, C.; Arenz, M.; Segner, H. Comparative Study of Cytotoxicity By Platinum Nanoparticles and Ions In Vitro Systems Based on Fish Cell Lines. Toxicol. In Vitro 2020, 66, 104859. [CrossRef]

57. Gehrke, H.; Pelka, J.; Hartinger, C.G.; Blank, H.; Bleimund, F.; Schneider, R.; Gerthsen, D.; Bräse, S.; Crone, M.; Türk, M. Platinum Nanoparticles and Their Cellular Uptake and Dna Platination At Non-Cytotoxic Concentrations. Arch. Toxicol. 2011, 85, 799-812. [CrossRef]

58. Seiberg, M. Keratinocyte-Melanocyte Interactions During Melanosome Transfer. Pigment Cell Res. 2001, 14, 236-242. [CrossRef]

59. Delevoye, C. Melanin Transfer: The Keratinocytes Are More Than Gluttons. J. Investig. Dermatol. 2014, 134, 877-879. [CrossRef]

60. Hirobe, T. Keratinocytes Regulate the Function of Melanocytes. Dermatol. Sin. 2014, 32, 200-204. [CrossRef]

61. Shah, A.N.; Marfatia, R.K.; Saikia, S.S. A Study of Noncultured Extracted Hair Follicle Outer Root Sheath Cell Suspension for Transplantation In Vitiligo. Int. J. Trichology 2016, 8, 67. [CrossRef]

62. Tobin, D.J.; Paus, R. Graying: Gerontobiology of the Hair Follicle Pigmentary Unit. Exp. Gerontol. 2001, 36, 29-54. [CrossRef]

63. Campbell, K.I.; George, E.L.; Hall, L.L.; Stara, J.F. Dermal Irritancy of Metal Compounds. Studies with Palladium, Platinum, Lead, and Manganese Compounds. Arch. Environ. Health 1975, 30, 168-170. [CrossRef] [PubMed]

64. Czubacka, E.; Czerczak, S. Are Platinum Nanoparticles Safe To Human Health? Med. Pr. 2019, 70, 487-495. [CrossRef]

65. Shibuya, S.; Watanabe, K.; Tsuji, G.; Ichihashi, M.; Shimizu, T. Platinum and Palladium Nanoparticle-Containing Mixture, Paplal, Does Not Induce Palladium Allergy. Exp. Dermatol. 2019, 28, 1025-1028. [CrossRef] [PubMed]

66. Aygun, A.; Gülbagca, F.; Ozer, L.Y.; Ustaoglu, B.; Altunoglu, Y.C.; Baloglu, M.C.; Atalar, M.N.; Alma, M.H.; Sen, F. Biogenic Platinum Nanoparticles Using Black Cumin Seed and Their Potential Usage as Antimicrobial and Anticancer Agent. J. Pharm. Biomed. Anal. 2020, 179, 112961. [CrossRef]

67. Naseer, A.; Ali, A.; Ali, S.; Mahmood, A.; Kusuma, H.; Nazir, A.; Yaseen, M.; Khan, M.; Ghaffar, A.; Abbas, M. Biogenic and Eco-Benign Synthesis of Platinum Nanoparticles (Pt Nps) Using Plants Aqueous Extracts and Biological Derivatives: Environmental, Biological and Catalytic Applications. J. Mater. Res. Technol. 2020, 9, 9093-9107. [CrossRef]

68. Joshi, P.G.; Nair, N.; Begum, G.; Joshi, N.B.; Sinkar, V.P.; Vora, S. Melanocyte-keratinocyte interaction induces calcium signalling and melanin transfer to keratinocytes. Pigment Cell Res. 2007, 20, 380-384. [CrossRef] [PubMed]

Publisher's Note: MDPI stays neutral with regard to jurisdictional claims in published maps and institutional affiliations.

(C) 2020 by the authors. Licensee MDPI, Basel, Switzerland. This article is an open access article distributed under the terms and conditions of the Creative Commons Attribution (CC BY) license (http://creativecommons.org/licenses/by/4.0/). 